\title{
High-Frequency Oscillatory Ventilation (HFOV) in preterm infants: Nursing management experience of a I I I-level Neonatal Intensive Care Unit (NICU) at the Catholic University of the Sacred Heart of Rome
}

\author{
Giovanni Vento, Milena Tana, Alessandra Gianduzzo, Luca Di Sarra, Martina Querini, Luana Di \\ mastrogiovanni, Chiara Tirone, Claudia Aurilia, Alessandra Lio, Sarah Perelli, Cinzia Ricci, \\ Costantino Romagnoli
}

Division of Neonatology, Policlinico A. Gemelli, Università Cattolica S. Cuore, Rome, Italy

Correspondence: Giovanni Vento, M.D. Address: Division of Neonatology, Department of Pediatrics, Policlinico A. Gemelli-Università Cattolica S. Cuore Largo A. Gemelli, 800168 Rome, Italy. Telephone: 39-063-015-4357. Email: vento@rm.unicatt.it.

Received: March 12, 2013

DOI : $10.5430 /$ jnep.v4n1p62
Accepted: April 23, $2013 \quad$ Online Published: June 3, 2013

URL: http://dx.doi.org/10.5430/jnep.v4n1p62

\section{Abstract}

Background: During the last years High Frequency Oscillatory Ventilation (HFOV) has been increasingly used in preterm infants with respiratory failure. In our Neonatal Intensive Care Unit (NICU) newborns with gestational age (GA) $\leq 27$ weeks and/or birth weight $(\mathrm{BW})<1000 \mathrm{~g}$ requiring mechanical ventilation, are electively treated with HFOV, performed with Draeger Babylog 8000 plus. Specific knowledge regarding optimal methods for setting and managing HFOV involves both physicians and nurses. Nursing considerations for the use of HFOV to detect changes in condition and to prevent complications in a high risk population, such as patients of NICU, are strongly needed. Furthermore data on weaning and extubation criteria are limited, especially in extremely low birth weight (ELBW) infants. Objective of this study was to evaluate the HFOV major nursing issues in the light of a more than ten years' experience in the management of preterm infants (GA $\leq 27$ weeks) and/or $\mathrm{BW}<1000 \mathrm{~g}$ who require invasive respiratory assistance and managed with HFOV as a primary mode of ventilation.

Methods: We described some key points of nursing care of preterm infants HFOV ventilated: airways, circulation, care, postures and patients comfort. All preterm infants directly extubated from HFOV between June 2006 and June 2009 were included into this retrospective cohort study. Extubation was attempted when continuous distending pressure (CDP) was $\leq$ $6 \mathrm{cmH}_{2} \mathrm{O}, \mathrm{FiO}_{2} \leq 0.25$ and Amplitude $\leq 30 \%$. Data on ventilator setting and gas exchange parameters just prior to extubation were collected by reviewing respiratory sheets.

Results: Fifty-eight patients of 73 electively treated with HFOV (79.5\%) were directly extubated from HFOV: 53 (91\%) were successfully extubated and $5(9 \%)$ required re-intubation within the following 72 hours for hypercapnia $\left(\mathrm{pCO}_{2}>70\right.$ $\mathrm{mmHg}$ ). No significant differences were found between Extubation Success and Extubation Failure Groups in terms of GA ( $26.2 \pm 1.3$ vs $25.8 \pm 1.3$ weeks, respectively), BW ( $770 \pm 204$ vs $614 \pm 193 \mathrm{~g}$, respectively), day of extubation (3 [1-53] vs 3 [2-10], respectively). The only different parameter between Extubation Success and Extubation Failure Groups was $\mathrm{DCO}_{2}\left(\mathrm{Vt}^{2} \mathrm{xHz} / \mathrm{kg}\right)$ before extubation, significantly higher in the first Group: $30 \pm 10$ vs $18 \pm 12(p<0.05)$. 
Conclusions: In electively HFOV ventilated ELBW infants, weaning the $\mathrm{CDP} \leq 6 \mathrm{cmH}_{2} \mathrm{O}$ with $\mathrm{FiO}_{2} \leq 0.25$ is feasible and extubation at this setting is successful in $91 \%$ of our ELBW infants.

\section{Key words}

HFOV, Premature infants, Extubation criteria

\section{Introduction}

High frequency oscillatory ventilation (HFOV) has been used for more than 20 years in the treatment of RDS of very preterm infants; it provides a variable continuous distending pressure (CDP) and delivers minute tidal volumes, even less than pulmonary anatomic dead space. HFOV permits the lungs to remain open during the entire respiratory cycle and rules out the stretching of distal airways involved in the pathogenesis of both lung injury ${ }^{[1,2]}$ and bronchopulmonary dysplasia (BPD).

In our Neonatal Intensive Care Unit (NICU), HFOV is actually the elective modality of ventilation in newborns with gestational age $(\mathrm{GA}) \leq 27$ weeks as a consequence of our previous randomized controlled trial, comparing the effects of HFOV vs CMV ${ }^{[3]}$. The results of this study supported the hypothesis that early and exclusive use of HFOV, combined with optimal lung volume strategy achieving a $\mathrm{FiO}_{2} \leq 0.25$ during the recruitment procedure, has a beneficial effect during the acute phase of lung injury.

Specific knowledge regarding optimal methods for setting and managing HFOV involves both physicians and nurses. In particular, nursing considerations for the use of HFOV to detect changes in condition and to prevent complications in a high risk population, such as patients of NICU, are strongly needed. Several papers ${ }^{[4,5]}$, also argue that the nursing intervention was demonstrated as a crucial factor in the success of the extubation of the preterm infant.

Objective of this study was to evaluate the HFOV major nursing issues in the light of a more than ten years' experience in the management of preterm infants of very low gestational age ( $\leq 27$ weeks) and / or very low birth weight $(<1000 \mathrm{~g})$, who require invasive respiratory assistance and managed with HFOV as a primary mode of ventilation.

\section{Key points to be evaluated at any time assistance}

\section{Airways}

Carefully consider the "cleaning" of the airways: Run a toilet of the endotracheal tube because the presence of secretions reduces the delivered flow, and therefore the effectiveness of HFOV. To clear secretions in ventilated preterms infants from the endotracheal tube (ETT) and airways we use closed suction system; avoiding the disconnection of the circuit, pressures are preserved, even if modified. This aspect is even more important during HFOV, particularly for the importance of maintaining an adequate and constant lung volume, typical of this type of ventilation. The choice of catheter size depends on the size of the tube and the consistency of secretions. In the NICU, maintaining ETT patency is critical for patients receiving assisted ventilation. The patients in whom small-sized ETTs are used, ETT suction is especially critical to avoid tube obstruction. In clinical practice and in the literature, two methods of ETT suctioning are described. The first technique is open suctioning in which the infant is disconnected from the ventilator to insert the suction catheter into the ETT. The second technique is closed suctioning (CS) in which devices are used allowing the nurse to insert the suction catheter without disconnecting the infant from the ventilator ${ }^{[6]}$. Both techniques have been extensively studied in the adult population and minimally in the newborn population. One study demonstrated overall better physiologic stability in infants suctioned with the CS technique as compared with those suctioned with open suctioning; these researchers also noted improved recovery time with CS, especially in infants less than $1000 \mathrm{~g}{ }^{[7]}$. Some authors ${ }^{[8]}$ recommend that closed suction devices be used to limit the lung volume loss when infants are removed from the ventilator. The Cochrane 
review ${ }^{[9]}$ does not make a recommendation for clinical practice regarding closed vs open systems because the studies are small, and some of them with methodological design problems, and because infants less than 28 weeks also need to be included in the trials. Use the larger possible endotracheal tube to ventilate the baby-compatible with his airway(reasonably it should always be avoided to ventilate a newborn with a tube of caliber $2.0 \mathrm{Ch}$ ). During the HFOV the resistance of the endotracheal tube is flow-dependent and can be described using the constants of Rohrer: R: $1 / \mathrm{r} 4$. The presence of secretions or a small diameter of the endotracheal tube will therefore determine a significant reduction in the amplitude of the oscillations, therefore of flow and Tidal volume (VT). A correct and adequate cleaning of the tube is critical in HFOV more than in conventional mechanical ventilation (CMV). With the latter, the removal of $\mathrm{CO}_{2}$ is proportional to the alveolar minute ventilation (product of respiratory rate by the tidal volume: $\mathrm{fx} \mathrm{V}_{\mathrm{T}}$ ). With all devices $\mathrm{HFOV}, \mathrm{CO}_{2}$ removal is proportional to the product of the frequency by the square of the tidal volume $\left(\mathrm{f} \mathrm{V}_{\mathrm{T}}{ }^{2}\right)$. In clinical practice, small changes in the amplitude of HFOV (usually measured as $\triangle \mathrm{P}$ ) or $\mathrm{V}_{\mathrm{T}}$ have major effects on $\mathrm{CO}_{2}$ elimination. The adequacy of ventilation needs to be carefully assessed by evaluating the chest wall movements: we have to see the infant's chest to be "bouncing". The "optimal" time to perform a toilet of the endotracheal tube will depend on a series of key factors: a) adequacy of chest movements, well visible; b) $\mathrm{SpO}_{2}$ values; c) chest auscultation, to evaluate both the "quality" and the symmetry of sound transmission; d) the wave flow on the screen of the ventilator and e) $\mathrm{DCO}_{2}$ and $\mathrm{V}_{\mathrm{T}}$ values. When these values fall or when the wave is jagged, is the time to proceed to the suction. In fact, for each patient, a value of normocapnia corresponds to specific values of $\mathrm{DCO}_{2}$ and $\mathrm{V}_{\mathrm{T}}$ (normally, 40-60/kg and 1.5-2 $\mathrm{ml} / \mathrm{kg}$, respectively). A sudden decrease of their values is usually an early sign of impaired ventilation, requiring suction. Excellent humidifycation is essential with such high flow oscillators, as necrotizing tracheo-bronchitis has been reported with high frequency jet and oscillator ventilation ${ }^{[10]}$; this problem appears to relate to a combination of dry gas and high inspiratory flow. The neonatal nurse must therefore ensure that airway temperature is maintained at 37 degrees and the fluid level in the humidification chamber is checked and refilled.

\section{Circulation}

Assess ALWAYS the cardiovascular function and an adequate perfusion, by monitoring blood pressure, venous pressure, heart rate and time to "refill" the skin (normal capillary filling $\leq 3$ "). In particular the major signs of severe circulatory shock should always be checked: prolonged capillary filling, reduced strength of peripheral pulses, cool skin, lethargy, hypotension, oliguria, increasing lactate concentrations and metabolic acidosis Echocardiography also provides information useful for the assessment of cardiac contractility and filling state of the ventricles ${ }^{[1]}$. In case of inadequate perfusion and/or hypotension, perform a bolus of normal saline ( $10 \mathrm{ml} / \mathrm{kg}$ ) in 20'-30' (up to a maximum of 3 boluses/day), then use dopamine or dobutamine as clinically indicated.

\section{Care, postures and patient comfort}

It's important to ensure the newborn a state of calm with the daily care, reducing non-essential sounds and light stimulation. Use of sedation and close observation of reactions in children is strongly encouraged: irritability, activities and opposition to the respirator, as well as a positive pain score, must be notified immediately to the responsible physician. On the other hand, unlike adults requiring HFOV, who have usually their spontaneous respiratory efforts suppressed, neonates are "encouraged" to breath spontaneously while receiving HFOV. In this way, they contribute actively to obtain and maintain an optimal functional residual capacity (FRC), mandatory for a successful extubation. For this reason it's discouraged to deeply sedate the babies.

It should be maintained the correct posture of the newborns during the daily care, by checking the status of the skin and the position of the head because edema and skin necrosis can occur as a consequence of poor circulation.

The supine position is sometimes preferred by nurses for easier control of thoracic excursions, but we must ensure the alternation of the postures during the 24 hours, also with the help of postural aids (nests, bearings, rolls, drapes). On the other hand, the advantages of prone positioning are widely documented, and recognised in BAPM guidelines ${ }^{[12]}$. Prone 
positioning is associated with higher lung volumes and better oxygen saturation in oxygen dependent infants ${ }^{[13]}$. Some authors found that infants showed fewer signs of stress when prone, and suggested this was due to better flexion and containment ${ }^{[14]}$. However it would appear that despite this evidence, supine positioning did not significantly contribute to extubation failure.

\section{Parents}

While managing an unstable neonate, the nurse must also support the infant's family members, who are frequently frightened by the amount of equipment and expertise needed to care for their baby. An explanation of the environment surrounding the infant is important ${ }^{[15]}$. Good nursing practice and ethical conscience requires that parents be kept informed of their infant's progress and treatments ${ }^{[16]}$.

For families of critically ill patients, the NICU is very often an unknown, overwhelming, and difficult place. Like those of other patients, the parents of the newborn receiving HFOV must have ongoing two-way communication with the healthcare team. In addition, we believe that it is important to explain in understandable terms to the families how HFOV differs from normal ventilation and reasons why their child has been commenced on this therapy. Moreover, it is important to explain the need for sedation and analgesia, why they cannot hold their child whilst on this therapy, but can talk to and touch their child to provide comfort.

An important task of the nurse is to allow parents to be present as close as possible to the incubator, and to observe care during the maneuvers: this will allow them to mitigate the anxiety and worry, feelings caused by the sight of their child subjected to ventilation in HFOV which represents a big and strong emotional impact. Finally, additional purposes of nursing care are also fostering relationships with their child (bonding), as well as establish a relaxed and trust between health staff and families, allow and encourage parents to verbalize their anxiety, fears and concerns ${ }^{[18]}$.

\section{HFOV strategy}

In our NICU preterm infants with GA $\leq 27$ weeks and/or birth weight $<1000 \mathrm{~g}$ requiring on-going intensive care, are electively ventilated using $\mathrm{HFOV}^{[3]}$. HFOV was delivered with a Draeger Babylog 8000 plus ventilator (Dräger, Lubeck, Germany) using an "Optimal Lung Volume Strategy" (OLVS), as previously reported. Briefly, the aim of this strategy was to recruit collapsed alveoli using oxygenation as an indirect parameter for lung volume. Ventilation was started with a $\mathrm{CDP}$ of $10 \mathrm{~cm} \mathrm{H}_{2} \mathrm{O}$, a frequency of $10 \mathrm{~Hz}$, and amplitude, set at $30 \%$ at beginning, increased if necessary until the infant's chest was seen to be "bouncing". The $\mathrm{FiO}_{2}$ was initially set to ensure adequate oxygenation $\left(\mathrm{SpO}_{2} 85 \%-93 \%\right.$ and transcutaneous partial pressure of $\mathrm{O}_{2}\left(\mathrm{TcPO}_{2}\right)$ and $/$ or $\left.\mathrm{PaO}_{2} \geq 50 \mathrm{mmHg}\right)$. If the $\mathrm{FiO}_{2}$ was $>0.25$, the $\mathrm{CDP}$ was increased by $1.0 \mathrm{~cm}$ $\mathrm{H}_{2} \mathrm{O}$ every 2-3 minutes until $\mathrm{FiO}_{2}$ was $\leq 0.25$. This approach provides a more effective means to recruit and protect acutely injured lungs. Although the subgroup analysis for the adopted HFOV ventilation strategy (high volume strategy vs no high volume strategy) recently performed by a systematic review and meta-analysis of individual patients' data ${ }^{[19]}$ showed no benefits of an high volume strategy like the one used in our Unit, a clear $\mathrm{FiO}_{2}$ target to define optimal lung recruitment was not reported among trials intending to apply an open lung strategy, while trials that did define the $\mathrm{FiO}_{2}$ targets showed considerable variations in defining optimal lung volumes by oxygenation targets, with only four RCTs using an $\mathrm{FiO}_{2}$ of $\leq$ 0.30. According to our departmental protocols, all the babies are weaned and directly extubated from HFOV when a CDP $\leq 6 \mathrm{cmH}_{2} \mathrm{O}$ and $\mathrm{FiO}_{2} \leq 0.25$ are reached. Between 1 June 2006 and 30 June 2009, 73 preterm infants with GA $\leq 27$ weeks requiring endotracheal intubation for respiratory failure within 24 hours of life were admitted to our NICU and electively ventilated by HFOV. Fifty-eight patients of these (79.5\%) were directly extubated from HFOV. Fifteen preterm infants (20.5\%) were switched and subsequently extubated from CMV because of hypercapnia not responding to increased Amplitude or decreased Frequency [n. 6], attempt to improve hemodynamic instability [n. 2] and not documented reasons [n.7]. In 53 of the 58 preterm infants directly extubated from HFOV (91\%) the extubation was succesfull (Extubation 
Success Group) while 5 newborns (9\%) required re-intubation within the following 72 hours for hypercapnia $\left(\mathrm{pCO}_{2}>70\right.$ $\mathrm{mmHg}$ ) (Extubation Failure Group). No significant differences were found between Extubation Success Group and Extubation Failure Group in terms of GA ( $26.2 \pm 1.3$ vs $25.8 \pm 1.3$ weeks, respectively), BW (770 \pm 204 vs $614 \pm 193 \mathrm{~g}$, respectively), day of extubation (3 [1-53] vs 3 [2-10], respectively) (see Table 1). The only different parameter between Extubation Success and Extubation Failure Groups was $\mathrm{DCO}_{2}\left(\mathrm{Vt}^{2} \mathrm{xHz} / \mathrm{kg}\right)$ before extubation, significantly higher in the first Group: $30 \pm 10$ vs $18 \pm 12(p<0.05)$.

Table 1. Patients characteristics and ventilator setting at extubation time. Values expressed as mean \pm SD and median [range].

\begin{tabular}{llll}
\hline & $\begin{array}{l}\text { Extubation Succesfull Group } \\
\text { (N 53) }\end{array}$ & $\begin{array}{l}\text { Extubation Failure Group } \\
\text { (N 5) }\end{array}$ & p value \\
\hline GA (weeks) & $26.2 \pm 1.3$ & $25.8 \pm 1.3$ & 0.50 \\
$\mathrm{BW}(\mathrm{g})$ & $770 \pm 204$ & $614 \pm 193$ & 0.10 \\
Extubation day & $3[1-53]$ & $3[2-10]$ & 0.79 \\
$\mathrm{CDP}\left(\mathrm{cmH}_{2} \mathrm{O}\right)$ & $5.9 \pm 0.7$ & $5.5 \pm 0.5$ & 0.21 \\
Amplitude $(\%)$ & $35 \pm 16$ & $28 \pm 3$ & 0.33 \\
Frequency $(\mathrm{Hz})$ & $9 \pm 1$ & $9.6 \pm 1$ & 0.20 \\
$\mathrm{~V}_{\mathrm{T}} \mathrm{HFOV}(\mathrm{ml} / \mathrm{kg})$ & $2.0 \pm 0.5$ & $1.6 \pm 0.7$ & 0.10 \\
$\mathrm{DCO}_{2}\left(\mathrm{~V}_{\mathrm{T}}{ }^{2} \mathrm{x} \mathrm{Hz} / \mathrm{kg}\right)$ & $30 \pm 10$ & $18 \pm 12$ & $\mathbf{0 . 0 1}$ \\
\hline
\end{tabular}

\section{Conclusions}

In electively $\mathrm{HFOV}$ ventilated ELBW infants, weaning the $\mathrm{CDP} \leq 6 \mathrm{cmH}_{2} \mathrm{O}$ with $\mathrm{FiO}_{2} \leq 0.25$ is feasible and extubation at this setting is successful in $91 \%$ of our ELBW infants.

\section{References}

[1] Jackson JC, Truog WE, Standaert TA, Juul SE, Murphy JH, Chi EY, et al. Effect of High-Frequency Ventilation on the Development of Alveolar Edema in Premature Monkeys at Risk for Hyaline-Membrane Disease. Am Rev Respir Dis. 1991 Apr; 143(4): 865-71. PMID: WOS: A1991FE78100029. English. http://dx.doi.org/10.1164/ajrccm/143.4_Pt_1.865

[2] Meredith KS, deLemos RA, Coalson JJ, King RJ, Gerstmann DR, Kumar R, et al. Role of lung injury in the pathogenesis of hyaline membrane disease in premature baboons. Journal of applied physiology. 1989 May; 66(5): 2150-8. PMid:2745284

[3] Vento G, Matassa PG, Ameglio F, Capoluongo E, Zecca E, Tortorolo L, et al. HFOV in premature neonates: effects on pulmonary mechanics and epithelial lining fluid cytokines. A randomized controlled trial. Intensive care medicine. 2005 Mar; 31(3): $463-70$. PMID: 15717206. http://dx.doi.org/10.1007/s00134-005-2556-x

[4] Vandertak K. Collaborative extubation; best practice? J. Neonatal Nurs. 2008; 14 (5): 166-69. http://dx.doi.org/10.1016/j.jnn.2008.05.001

[5] West G, Pope A. Factors promoting successful extubation: An audit of planned extubations in preterm infants following the implementation of nursing guidelines. Journal of Neonatal Nursing. 2010 Dec; 16 (6): 267-73. http://dx.doi.org/10.1016/j.jnn.2010.07.019

[6] Clifton-Koeppel R. Endotracheal Tube Suctioning in the Newborn: A Review of the Literature. Newborn and Infant Nursing Reviews. 2006; 6(2): 94-9. http://dx.doi.org/10.1053/j.nainr.2006.03.006

[7] Kalyn A, Blatz S, Sandra F, Paes B, Bautista C. Closed suctioning of intubated neonates maintains better physiologic stability: a randomized trial. Journal of perinatology: official journal of the California Perinatal Association. 2003 Apr-May; 23(3): $218-22$. PMID: 12732859. http://dx.doi.org/10.1038/sj.jp.7210883

[8] Choong K, Chatrkaw P, Frndova H, Cox PN. Comparison of loss in lung volume with open versus in-line catheter endotracheal suctioning. Pediatric critical care medicine: a journal of the Society of Critical Care Medicine and the World Federation of Pediatric Intensive and Critical Care Societies. 2003 Jan; 4(1): 69-73. PubMed PMID: 12656547. 
[9] Taylor JE, Hawley G, Flenady V, Woodgate PG. Tracheal suctioning without disconnection in intubated ventilated neonates. Cochrane Db Syst Rev. 2011 (12). PMID: WOS: 000300937600015. English. http://dx.doi.org/10.1002/14651858.CD003065.pub2

[10] Levin DL, Morris FC. Essentials of Paediatric Intensive Care, 2nd ed. 1997. Churchill Livingstone, New York.

[11] Smeding L, Lust E, Plotz FB, Groeneveld AB. Clinical implications of heart-lung interactions. The Netherlands journal of medicine. 2010 Feb; 68(2): 56-61. PMID: 20167956.

[12] BAPM, 2005. Positioning and individualised care in babies with RDS. Available from: http://www.bapm.org/media/documents/ members/rds/RDS07_positioning-individualised-care.pdf.

[13] Kassim Z, Donaldson N, Khetriwal B, Rao H, Sylvester K, Rafferty GF, et al. Sleeping position, oxygen saturation and lung volume in convalescent, prematurely born infants. Archives of disease in childhood Fetal and neonatal edition. 2007 Sep; $92(5)$ : F347-50. PubMed PMID: 17012305. Pubmed Central PMCID: 2675354. http://dx.doi.org/10.1136/adc.2006.094078

[14] Chang YJ, Anderson GC, Lin CH. Effects of prone and supine positions on sleep state and stress responses in mechanically ventilated preterm infants during the first postnatal week. Journal of advanced nursing. 2002 Oct; 40(2): 161-9. PMID: 12366646. http://dx.doi.org/10.1046/j.1365-2648.2002.02358.x

[15] Williams LJ, Shaffer TH, Greenspan JS. Inhaled nitric oxide therapy in the near-term or term neonate with hypoxic respiratory failure. Neonatal network: NN. 2004 Jan-Feb; 23(1): 5-13. PMID: 14974765. http://dx.doi.org/10.1891/0730-0832.23.1.5

[16] Emery M. Informed consent: keeping parents in the picture. Journal of Neonatal Nursing 2000; 6 (3): 90-2.

[17] McDonagh JR, Elliott TB, Engelberg RA et al. Family satisfaction with families conferences about end-of-life care in the intensive care unit: increased proportion of family speech is associated with increased satisfaction. Crit Care Med. 2004; 32: 1484-1488. http://dx.doi.org/10.1097/01.CCM.0000127262.16690.65

[18] Higginson RJ. High Frequency Oscillatory Ventilation. The Internet Journal of Emergency and Intensive Care Medicine. 2003; 6(2). http://dx.doi.org/10.5580/e01. Available from:

http://www.ispub.com/journal/the-internet-journal-of-emergency-and-intensive-care-medicine/volume-6-number-2/high-frequen cy-oscillatory-ventilation.html\#sthash.LtC0ZKTu.dpuf.

[19] Cools F, Askie LM, Offringa M, Asselin JM, Calvert SA, Courtney SE, et al. Elective high-frequency oscillatory versus conventional ventilation in preterm infants: a systematic review and meta-analysis of individual patients' data. Lancet. 2010 Jun 12 ; 375(9731): 2082-91. PMID: 20552718. http://dx.doi.org/10.1016/S0140-6736(10)60278-4 